Las civilizaciones arcaicas, entendidas como aquellas sociedades tradicionales que hasta hoy conciben su mundo -en función del tiempo y el espacio- como un eterno ciclo, buscan su permanencia y desarrollo en el espacio natural lo que surge de un hecho común: La observación constante de la naturaleza, y con detenida atención, de los objetos y acontecimientos que ocurren en el cielo. Es así que nace una visión estructurada de la naturaleza, manera de concebir el espacio y sus objetos, el mito.

El mito, entendido como una interpretación de la naturaleza y sus objetos, a los cuales el hombre dota de forma sensible y corpórea de deidades, por una parte, genera un modo particular de concebir el espacio, donde los cuerpos geográficos de altura se constituyen en puntos de referencia en el territorio, como a su vez, en soportes situantes y de significado dentro de un sistema de culto mitológico.

Por otra parte, el mito provoca en las personas una forma de desenvolvimiento en el espacio, crea modos particulares de actuar en él: La danza, el juego, el sacrificio, todos actos rituales incorporados a una estructura

\title{
Cielo Mitológico. Orientación y Situación en el Origen de la Obra Arquitectónica en el Territorio. Extracto de seminario ucu/Ricardo Zepeda
}

\section{DOI: $10.22199 / S 071985890.2006 .0010 .00015$}

Al preguntar por el origen de la obra de arquitectura en el territorio, se está interrogando por la relación que la obra establece con el espacio natural. Más allá de la ubicación en el territorio como circunstancia vital, se interroga por la orientación y situación que la obra establece en determinado territorio, en función al modo que el ser humano se orienta y sitúa en el espacio, manera de adaptación y dominio, a la forma de concebirlo. Así la orientación y situación de la obra surge de la relación hombre y espacio natural.

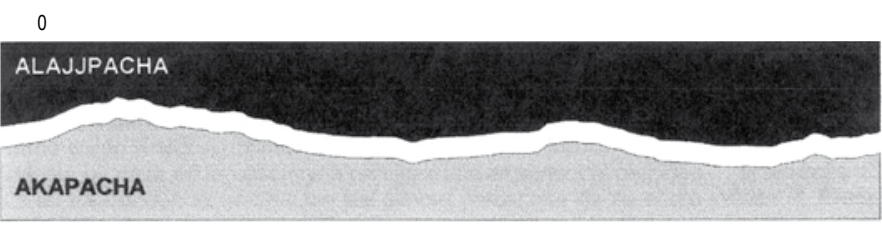

MANKHAPACHA

Tutores / Ignacio Millán, Vladimir Misetic, Claudio Ostria.

mayor, la festividad, develan la capacidad que tiene el cuerpo, en función del mito, para orientarse y situarse en el espacio, no tan sólo haciéndolo tangible, sino también entregándole la capacidad de configurar lugares en el territorio.

De este modo, el seminario inicia la búsqueda de aquellos elementos del cielo mitológico que permiten al hombre concebir el espacio natural $y$, a su vez, situar determinados hechos en el territorio, como la obra de arquitectura, con una determinada orientación en el espacio.

\section{Concepción del Espacio / Espacio Natural}

"Origen es aquello a partir de donde y por lo que una cosa es y tal como es... el origen de algo es la fuente de su esencia"1. El origen de la obra de arquitectura en el espacio natural está en la orientación y situación que la obra establece en dicho espacio. La orientación y situación de la obra surge en la medida en que el ser humano se establece en el territorio previamente, en cuanto se orienta y sitúa, determinando el espacio natural.

Se ha señalado que el espacio, por su naturaleza, es intangible e ilimitado, por lo tanto, el espacio aparece en la medida que las personas tengan la capacidad -de una u otra manera- de limitarlo, hacerlo tangible, por lo tanto, el espacio es "el producto de una interacción entre el organismo y el ambiente que lo rodea" ${ }^{2}$. La comprensión del espacio natural está en la capacidad que se tiene para orientarlo. El hombre en la naturaleza, experiencia prima con el espacio, la percibe como indeterminada. José Ricardo Morales se refiere al espacio indeterminado como vastedad: "Lo "inmenso" bajo el aspecto de "naturaleza". Piélago, estepa, desierto y selva son modalidades naturales de lo inmenso... La vastedad obliga a la indeterminación y a la vaguedad... En la vastedad nada se puede indicar o mostrar, nada se pronuncia o acusa, porque la vastedad es vaguedad". Además, agrega que la indeterminación del espacio natural -ó 


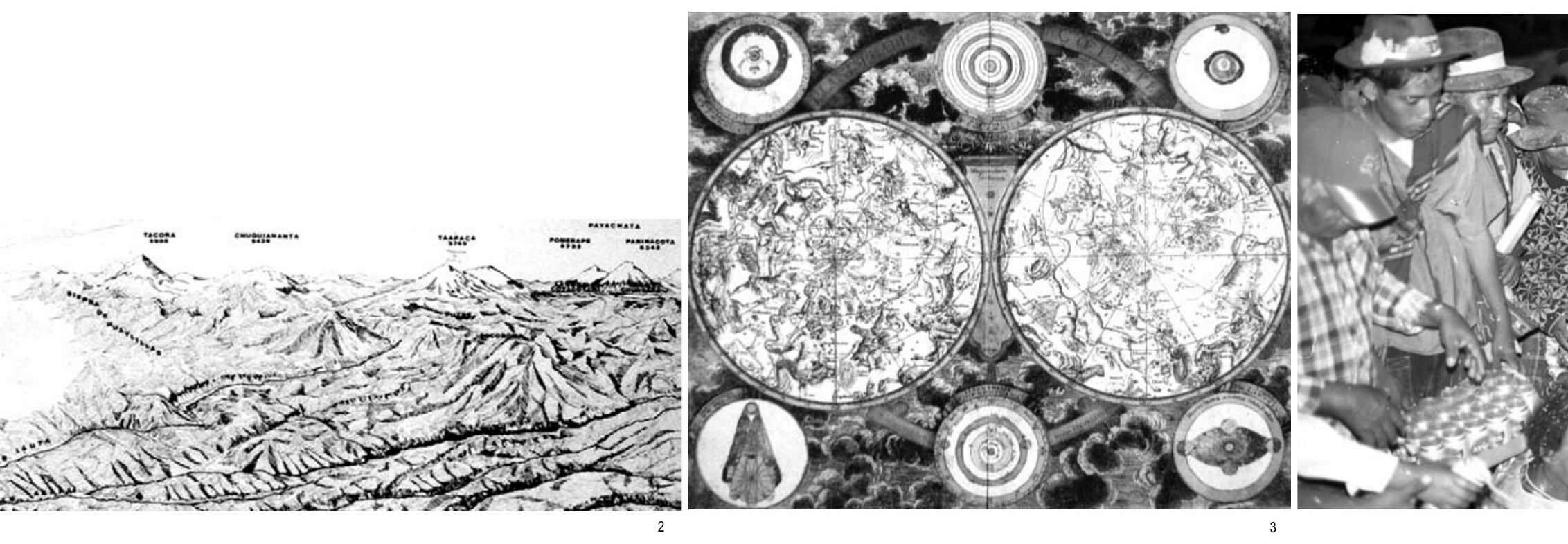

la desorientación del hombre- ocurre porque el espacio, a primera vista está carente de huellas, datos, signos, notas límites, líneas o puntos de remisión ${ }^{3}$. A esto, Ricardo Riesco agrega que el espacio geográfico no es apreciable de manera inmediata, menos de una forma única y totalitaria, por lo tanto, para tener noción del espacio es necesario revelarlo, depurarlo, orientarlo y dimensionarlo para así intentar hacerlo sensible en toda su magnitud al ojo del observador ${ }^{4}$. Con respecto al fenómeno de la desorientación, Riesco agrega: "En el espacio geográfico no hay arribas o abajos, no hay cercas ni lejos. Todo se relativiza y se conjuga en función de la situación del observador en el espacio geográfico con miras a un punto de referencia" ${ }^{\text {. }}$

De esta manera, el hombre mediante un ejercicio de remisión, comienza a determinar el espacio. Una forma de determinar el espacio natural es la creación de un límite aparente, dado por el horizonte perceptible. Entorno a esto, Morales señala qué: "Cuando tenemos presente de la vastedad su condición extensiva, la concebimos como un espacio a la redonda, en el que el horizonte establece, a distancia, la única referencia clara". Dentro de las prácticas para determinar el espacio natural, está la de remitirse a los objetos situados en el espacio circundante. La observación de ciertos astros -como es el caso del sol- a través de sus movimientos en el cielo y sus aparentes contacto con el límite perceptible entre cielo y geografía, no tan sólo permiten orientarse al hombre, sino también orientar el espacio, dándole dirección, sentido, medida con respecto a dichos objetos. "El indiferenciado espacio "a la redonda", se transforma en una extensión remitida a determinados puntos "cardinales"...,así que cuando el hombre se desplaza orientado en la vastedad, y la orienta y la dirige, la rige..., la rige seccionándolas en regiones...en la que no sólo se permite conocer un todo fragmentándolo por partes, sino que, además, puede situar cosas y personas en tal o cual parte" 6 .

El hombre, al estar orientado, puede concebir el espacio. Riesco señala que existen dos modos de concebir el espacio geográfico: Un modo en relación área-superficie (nivel a macro-escala), en el que se accede al concepto espacio a través de la noción de paisaje geográfico, en especial de la distinta sucesión y fisonomía; y por relación distancia-tiempo, mediación del uso de la noción de distancia, por ende, apelando al concepto de tiempo. "La noción de tiempo en la geografía queda definida por la velocidad en que se repite sistemáticamente un mismo fenómeno natural cósmico, como es el día y la noche o la estaciones del año"7. Este modo de concebir la naturaleza hace que se tenga dominio del espacio. A través de sus distintos actos, el hombre genera una forma de vida, "expresión de síntesis final entre su voluntad y las posibilidades que le brinda el escenario natural". Riesco acota que las diversas modalidades de forma de vida, representan instancias humanas colectivas de toma de conciencia del espacio geográfico, "ellas se enlazan con la geografía como ciencia, en la medida que tengan expresión espacial en la superficie terrestre, $y$ en le sentido que trasunten trabajo organizado del hombre" ${ }^{3}$. A través del tiempo, se han producido dos modos de desenvolvimiento del hombre en el espacio natural: Un modo de movilidad o trashumancia en el espacio geográfico, generando las formas de vida nómada; y un modo estático o de permanencia, dando origen a las formas de vida sedentaria. La relación que tiene el hombre-nómada con el espacio, está determinada por la movilidad de su actividad, ya sea productiva, a través de la búsqueda de alimento para el ganado o rebaño, o por el desplazamiento de las empresas en el pasado, como es el caso de "las cruzadas". El nomadismo, entendido como forma cultural de vida, por su movilidad, conlleva a entender la relación hombre-naturaleza como una permanente temporalidad, porque todo su quehacer y modo de permanencia es transitorio; esto se ve reflejado en el carácter móvil y efímero de su vivienda en el espacio geográfico. En las formas de vida sedentarias la relación hombre-naturaleza está determinada principalmente por la actividad de subsistencia, como es el caso de la agricultura, y el carácter estable de su vivienda. Riesco señala que el lazo que vincula la agricultura con el espacio geográfico es permanente, casi normativo, "adquiere su máximo testimonio fisonómico en la unidad indisoluble que conforma la habitación y el lugar de trabajo de los agricultores"9. El hombre comienza a situar de forma permanente elementos en la naturaleza a crear su mundo y constituir su territorio. Pero más allá de la necesidad de subsistencia, ¿qué es lo que determina que el ser humano se situé espacialmente y defina tal territorio?

\section{Concepción Mitológica del Espacio}

El mito es una interpretación de la realidad que surge de la observación de los objetos naturales, a los cuales el hombre les da forma sensible y corpórea de deidades. La observación de dichos objetos, primordialmente, trae consigo la toma de conciencia del espacio a través de la identificación de la situación de los objetos. De su concepción mítica el espacio adquiere forma-imaginaria, significación de lugar-sagrado: "Donde habitan los objetos-deidades". De este modo, el fenómeno de la observación devela una primera forma de hacer tangible el espacio, mediante la generación de un orden, dándole medida, límites, diferenciando el espacio circundante en regiones determinadas por la situación de los objetos-naturales. A la vez -de la interpretación mitológica de lo observado- aquellas regiones adquieren significación en la medida que son parte fundamental en el origen y situación del estar en el espacio natura geográfico, cuyos objetos se nutren de formas y cualidades corpóreas ya sean éstas de naturaleza animal, vegetal, incluso humana. 
estrellas y planetas; y un tercer cielo llamado "ALAJJPACHA", que esta referido a la condición infinita del cielo, considerado como el lugar donde viven los dioses y las almas ${ }^{17}$. Dentro de la concepción mitológica del cielo, el hombre-aymara, considerada esta región arquetipo, donde las constelaciones celestes se consideran prototipo de una especie animal, vegetal o un elemento de la naturaleza terrestre como puede ser un río, un lago, etc. ${ }^{18}$

Así el cielo es fundamental en la concepción del espacio natural y orientación en él, y en su ser mitológico, el cielo constituye parte fundamental de su mundo. El mito del cielo, más allá de ser entendido como una manera de concebir y explicar los fenómenos y objetos naturales que ocurren en el espacio natural, se constituye en una obra conceptualintangible, basada en formas antropomorfas y zoomorfas, que asume tanto las dimensiones físicas del espacio natural como la metafísica, a través de la divinización del movimiento de los objetos. Más allá de su naturaleza en el origen, como obra intangible, el mito tiene la capacidad de fijar el espacio, lo hace tangible, de manera que orienta y sitúa al hombre en él. Pero cabe preguntar si a partir de esta manera de concebir el espacio y lo que ocurre en él -creación de un mundo intangible, de una cosmovisión-, ¿el hombre es capaz de construir un mundo real, tangible, en la medida que hace aparecer la intangibilidad del mito?, ¿qué es lo que -en función del cielo mitológico- fija su mundo en la Tierra?, ¿qué es lo que determina su territorio?

\section{Geografía}

Respecto al espacio y el tiempo mítico, Johanna Broda señala: "La coordinación que existía entre el tiempo y el espacio en la cosmovisión mesoamericana, encontró su expresión en la arquitectura mediante la orientación de pirámides y sitios arqueológicos"19. A esto, Arturo Ponce de León agrega: "Son estos dos elementos, tiempo y espacio, los componentes esenciales en la arquitectura prehispánica... el tiempo, lugar y trayectoria en que sucedían los eventos mitológicos, determinó no solamente los sistemas calendáricos, sino también la erección de centros ceremoniales, como sitios geográficos-urbanísticos, que llegaron a ser un eficiente instrumento geométrico-astronómico para la medición de tiempo y el espacio" ${ }^{\prime 2}$. Así el mito, además, construye un mundo en el territorio, en función de los objetos y el espacio natural vinculados al cielo, y también tiene la capacidad de orientar y situar hechos construidos en el territorio, como lo es una obra de arquitectura.

Norberg-Schulz señala que el hombre en el espacio genera esquemas de orden mediante el establecimiento de "centros" o lugares, "direcciones" o caminos, y "áreas" o regiones. Agrega que "el centro no sólo se establece como un medio de organización general, sino que su situación en el espacio constituye un punto de referencia en el ambiente circundante"21. Dentro del proceso de adaptación y dominio en el espacio natural, a través de su concepción mitológica, los cuerpos geográficos desarrollan un papel determinante en la orientación y situación del hombre y su mundo en el espacio natural. Mediante la determinación de los objetos y acontecimientos celestes en cerros, volcanes, montañas, y principalmente en las altas cumbres circundantes, por una parte, hace tangible la posición del cuerpo astronómico de determinada fecha significativa en el territorio, constituyéndose el cuerpo geográfico en un punto de referencia de tiempo en el espacio, y por otra parte, el cuerpo geográfico de altura surge como soporte-situante y de significado en la creación de un sistema de culto a las deidades del cielo, mediante la orientación y situación de centros ceremoniales en ellos. Así el hombre carga de sentido y valor mítico a cerros, montañas, ríos, lagos, etc. Mircea Eliade indica que dichos elementos, para las culturas mesopotámicas y egipcias (como así también en las culturas prehispánicas en América), son una repetición de un arquetipo celeste, "para el hombre arcaico la tierra es una repetición de cielo, la tierra corresponde a una tierra celestial"22.

En las culturas andinas, los cuerpos geográficos más significativos, ya sean cerros, montañas o volcanes, son un punto de referencia en la orientación y concepción mitológica de su mundo en el espacio. En el caso de los Aymaras, los cerros y montañas más significativos en su entorno son denominados "Mallkus", significación mitológica en que se les considera "seres-protectores" de una comunidad; se conciben como "lugar-sagrado", en cuanto en ellos habitan los espíritus-tutelares de los antepasados denominados "Achachilas". Esta concepción del cuerpo geográfico, hoy se hace visible a través de la colocación de cruces y a partir de las festividades, cuando se asciende hasta ellos para celebrar los actos rituales.

Los cuerpos geográficos más elevados, adquieren tal significación sobre una mayor cantidad de comunidades circundantes. Es así que en el caso de la región de Tarapacá, los cuerpos geográficos más significativos son: El volcán "Tacora" y "Chuquinanta", en la comuna de Genera Lagos; "Los Taapaca”, "Payachatas", "Guallatire” y cerro "Márquez" en la comuna de Putre; "Itiza" y "Qolqa" en la comuna de Camarones; Volcán "Isluga" y "Tata Jachura" en la provincia de lquique. Esta concepción del territorio hace que exista, tanto una percepción a macro escala, como también a una micro escala del espacio natural.

Notas

El articulo corresponde a un extracto del Seminario aqui expuesto, Departamento de Arquitectura, UCN.

1. Heidegger Martin. El Origen de La Obra De Arte [En Línea]: http://personales.ciudad.com.ar/M_Heideggerl. [Consulta: 16 de Mayo de 2004]

2. Norberg-Schulz, Christian, Existencia, Espacio y Arquitectura, Barcelona: Blume, 1975, p.20.

3. Morales, José Ricardo, Arquitectónica, Sobre la Idea y el Sentido de la Arquitectura, Santiago: Universitaria, 1984, pp.173-179.

4. Riesco, Ricardo, "El Espacio en la Geografia", en El Espacio de las Ciencias, Problemas Fundamentales del Honbre, Santiago: Consejo de Rectores de las Universidades Chilenas / Universitaria, 1982, pp.193.

5. Riesco, Ricardo, "El Espacio en la Geografia", p.220.

6. Morales, José Ricardo, Arquitectónica, pp.176-177.

7. Riesco, Ricardo, "El Espacio en la Geografia", p. 196

8. Riesco, Ricardo, "El Espacio en la Geografia", p.213.

9. Riesco, Ricardo, "El espacio en la geografia", p. 217 .

10. Westheim, Paúl, Arte Antiguo de México, México: Fondo de Cultura Económica, 1963. p.72.

11. Mangino, Alejandro, Arquitectura Mesoamericana: Relaciones Espaciales, México: Ed. Trilla, 1990, pp.129-130.

12. Westheim, Paúl, Arte Antiguo, p.81

13. Centro de Cultura, Arquitectura y Arte Taipinquiri, La Cruz Escalonada Andina, Edición Centro de Cultura, Arquitectura y Arte Taipinquiri. p.69.

14. Eliade, Mircea, Tratado de Historia de las Religiones, México: Ediciones Era S.A. de C.V., 1996, p.64.

15. Eliade, Mircea, Tratado de Historia, p.59.

16. Mangino, Alejandro, Arquitectura Mesoamericana, p.131.

17. Loza-Balza, Gregorio, s.f. Astronomía Aymará, pp.4-5.

18. Centro de Cultura, Arquitectura y Arte Taipinquiri, La Cruz, p.67-68.

19. Broda, Johanna, "Cosmovisión y Observación de la Naturaleza, el Ejemplo del Culto de los Cerros", en Simposio de Arqueoastronomía y Etnoastronomía en Mesoamérica, 1984, México: Instituto de Investigaciones Antropológicas, Instituto de Investigaciones Históricas, Instituto de Astronomía, Universidad Nacional Autónoma de México, 1991.

20. Ponce de León, Arturo, "Propiedades Geométrico-Astronómicas en la Arquitectura Prehispánica", en Simposio de Arqueoastronomía y Etnoastronomía en Mesoamérica

21. Norberg-Schulz, Christian, Existencia, Espacio y Arquitectura, pp.20-21.

22. Eliade, Mircea, El Mito del Eterno Retorno, Madrid: Alianza, 1972 p.16.

\section{Imágenes}

0. Esquema espacial del cielo, según cosmovisión aymara. ๑ R. Zepeda.

1. Esquema espacial del cielo según cosmovisión aymara. $\odot$ R. Zepeda.

2. Cumbres mitológicas de la cordillera de los Andes, provincia de Parinacota, Primera Región

๑๑ Archivo digital http://www.muniarica.cl/mapas/region1.jpg.

3. Mapa celeste siglo XVII ๑ Archiv Für Kunst und Geschichte. Manual de los cielos y sus mitos,

Barcelona: Blume, 1999, p.8

4. Entierro del ser mítico "ño carnavalon". $\odot$ R. Zeped

5. Santa Cruz, Cerro Moreno, Valle de Azapa, Chile. @ R. Zepeda.

6. Cancha juego de pelota, Monte Albán, México.

(๑) http://studentweb.tulane.edu/ dhixson/montealban/ballcourt1.htm.

7. Procesión celebración "Cruz de Mayo", Cerro Moreno, Valle de Azapa, Chile. @ R. Zepeda.

8. Vista general Lago Chungará / Esquema espacial según cosmovisión aymara. @ R. Zepeda.

Ricardo Zepeda

Arquitecto Universidad Católica del Norte.

Docente Departamento de Arquitectura, UCN, Antofagasta, Chile. 